\section{Do better agricultural extension and climate information sources enhance adaptive capacity? A micro-level assessment of farm households in rural India}

\author{
Chandan Kumar Jha and Vijaya Gupta \\ National Institute of Industrial Engineering, Mumbai, India
}

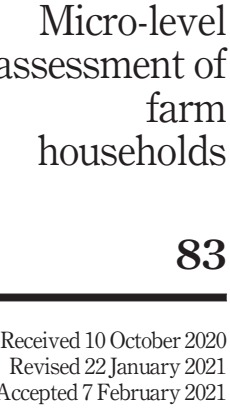

Revised 22 January 2021 Accepted 7 February 2021

\begin{abstract}
Purpose - The farmers used several information sources to gather information about the climatic variability and modern agricultural practices to cope with climate change. The choice of adaptation strategies and the successful implication of adaptation strategies depend on accurate, timely information on the climate variability and precise technical details of adaptation strategies. By keeping the importance of climate information and agricultural extension information in the center, this study aims to conduct a micro-level evaluation of farmers' choice of climate information, agriculture extension services and agricultural credit sources. This study's primary objective is to understand how the different sources of climate information and agricultural extension influence farm household adaptation decisions.
\end{abstract}

Design/methodology/approach - This study has been conducted in three subs agro-climatic zone of the Middle Gangetic Plain region, which falls in India's Bihar state. This paper has randomly selected seven districts from these three subs agro-climatic zone to collect the data. The analysis of this study is based on survey data collected from 700 farm households. This study has used descriptive statistics and a logistic regression model to assess the sources of climate information, agricultural extension and credit sources and how these sources influence farm households' adaptation decisions.

Findings - The result of this study shows farmers are using different traditional (sharing experience, newspaper and radio), information and communication technology (mobile and TV) and institutional arrangements (agricultural officer and meteorological department) in the study area. The study's finding identifies different farm households' different sources and how these options farming farmers' adaptation decisions. The study further revealed that institutional factors such as extension services and access to information on climate change increase the probability of adopting knowledge-intensive adaptation strategies such as soil conservation, water conservation, crop insurance and planting horticulture and vegetables.

Research limitations/implications - The study has conducted a micro-level assessment of adaptation behavior at the local level to understand the factor influencing the adaptation decision. This study's finding is useful in designing the appropriate policy framework for the farm household's

(c) Chandan Kumar Jha and Vijaya Gupta. Published in Ecofeminism and Climate Change. Published by Emerald Publishing Limited. This article is published under the Creative Commons Attribution (CC BY 4.0) licence. Anyone may reproduce, distribute, translate and create derivative works of this article (for both commercial and non-commercial purposes), subject to full attribution to the original publication and authors. The full terms of this licence maybe seen at http://creativecommons.org/ licences/by/4.0/legalcode

This study is a part of a $\mathrm{PhD}$ research at National Institute of Industrial Engineering, Mumbai, India. The authors acknowledge National Institute of Industrial Engineering, India for providing all the support to conduct this study. The authors also thank the respondents, villagers and officials for their unconditional support during data collection. The authors thank the anonymous reviewer for constructive suggestions and comments for improving the quality of this manuscript.

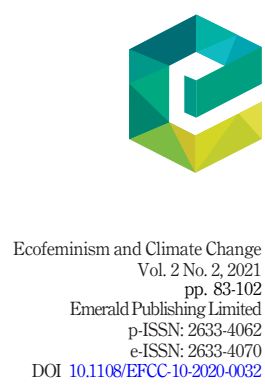


EFCC

2,2

84

capacity building to enhance their technical skills and awareness toward the institutional arrangements.

Originality/value - This paper's finding pointed out institutional arrangements' requirement to improve adaptive capacity to make long-term strategic decisions to cope with climate change.

Keywords Agricultural credit, Adaptation strategies, Agricultural extension, Climate information, Farm households

Paper type Research paper

\section{Introduction}

Climate change is the most significant market failure of all times (Stern and Stern, 2007), at the global level in its causes and consequences. The climate change predicament has driven extensive research of scientific, technical and socio-economic assessment of the complex interactions and changing the likelihood of its diverse impacts, more prominently over the past decade (IPCC, 2014). The commitment to ensure farmers' well-being and guarantee sustainability under the environmental stress due to climate change necessitates appropriate climate information on time and capacity building through advanced and contemporary agricultural extension services. Agriculture extension services and credit facilities are the two most enabling institutional arrangements that facilitate information delivery on new technologies and new farming practices (Ragasa et al., 2016; Nettle et al., 2017; Dunne et al., 2019). Access to agriculture extension services enhances farmers' awareness of changing climatic conditions and facilitates individual farmers' knowledge on different management practices that they can adapt to climate changes (Arbuckle et al., 2015). Thus, it helps farmers be timely, perceive changes in climatic events and modify their agronomic practices accordingly (Ramborun et al., 2019). It is essential to draw out the distinction between climate information sources and sources of agricultural knowledge as both complementary enables efficient adaptation.

The availability of farm extension services in a region depends on several factors such as adequate government intervention, institutional arrangements, technology penetration and personal relations. Mention in a more descriptive way, the government's active response such as agricultural officers' appointment, can remove the asymmetric flow of information among the farmers about the changing climate or available management and farm mechanization techniques. The agricultural educator's role is also vital to enhance rural communities' knowledge of global climate change in the food system. Technological innovations such as mobile also serve to be an effective medium of the flow of knowledge. How a farmer assembles, process and use climate information determines their adaptation actions. The efficiency and effectiveness of adaptation at the farm level are critically influenced by the level of certainty of climate perception and predictions at the regional scale (Pacey et al., 1989; Carswell and Jones, 2004). Information on climatic conditions is sequentially processed and used in active decision-making by farmers. The institutional arrangements can remove the asymmetric information related to changing climate or available management and farm mechanization techniques. Television, mobile, radio, newspapers are other well-acclaimed sources of information. Also, farmer-to-farmer extension services can play a significant role in deciding on effective adaptation strategies.

In light of the above debate, this paper first tried to identify climate information sources and agricultural extension assesses by farmers in the study area. Education level, land size and land rights are essential for evaluating the same. This paper examines how this medium of climate information and agricultural extension services play a role in adaptation decisions in the second stage. In Section 2, a brief review of the literature has been discussed. A short 
description of the study area and methodology has been given in Sections 3 and 4. In Section 5 , we have discussed the sources of climate information and agriculture extension assessed by the farm households in the study area and the importance of education level, land size and land rights. Section 6 presents agricultural extension and climate information sources in the farm household's adaptation strategy. The paper has been concluded in Section 6 with significant findings and policy implications.

\section{Literature review}

The broad spectrum of literature has mainly discussed the factors influencing the farm household's adaptive capacity to minimize climate change (Granjon, 1999; Hansen et al., 2004; Ziervogel et al., 2005; Vogel and O'Brien, 2006). Among these, the large number of literature has pointed out the high significance of agricultural extension, climate information services and credit facility in adaptation decisions among the farmers in a rural area and found to be diffusion tools of social capital into adaptation (Cooper et al., 2008; Deressa et al., 2008; Hammill et al., 2008; McLeman et al., 2008 Keil et al.,2008; Ziervogel et al., 2006; Di Falco et al., 2012 and Di Falco and Veronesi, 2013). These studies have also examined how the farm household's decision-making process is influenced by the use of information and in that the role of local knowledge was most important (Roncoli et al., 2001, 2002; Vogel and O'Brien, 2006). The decision to alter farming practices to cope with climate variability does not only depend on changes in the average condition but also the number of other climate variables such as erratic rainfall, extreme events, flood and drought (Smithers, 1997; Roncoli et al., 2002; Hansen et al., 2004; Thomas et al., 2007). The poor source of climate information and agricultural extension negatively impact farmers' well-being by affecting their capacity to cope with climate change (Roncoli et al., 2002; Hansen, 2007). Among the rural farmers, to improve the adaptive capacity, there is a need to enhance these sources (Vogel and O'Brien, 2006).

The climate information channels are community participation, individual capability and relationships, institutions and technology. The role of "indigenous knowledge" in climate forecasting has been identified by several studies (Roncolli et al., 2001; Ajibade and Shokemi, 2003). Indigenous knowledge involves a participatory approach of farmers or local communities to interpret seasonal fluctuations in climate and extremes such as a flood and drought, which helps in better farm management. Adger et al. (2003) has signified social capital as historical evidence and social networks' role in collective action for tackling climate hazards. Their capabilities and household relationship also determine farmer's decisions to adopt. Roncoli et al. (2001) observe that elderly male farmers of households often contemplate seasonal rainfall patterns through their experience of natural climate occurrences. The other sources of climate information can be weather information from government sources, nearby weather forecasting stations, television, news from radio and cellular devices. By underlying the importance of the formal and informal institution and social relationship, many studies have highlighted how the former can upscale adaptive capacity and shape the ability of farm households to respond to climate change and the adaptation strategies they choose (Agrawal, 2008; Agrawal and Perrin, 2008; Adger et al., 2003; Isham, 2002; Eakin, 2005). In the process to strengthen the adaptive capacity and the local level adaptation, the potential of institutional arrangements is also found necessary such as government extension services that provide awareness on farming practices in response to climate change (Adger et al., 2003; Agrawal, 2008; Agrawal and Perrin, 2008; Maddison, 2007; Nhemachena and Hassan, 2007).

Much of the literature evaluated socio-economic role in adaptation strategies and adaptive capacity has also empirically attempted to identify climate information and agricultural extension services. These studies have been first discussed theoretically
Micro-level assessment of farm households 
EFCC

2,2

\section{6}

and then investigate the role of several sources of climate information and agricultural extension as a variable related to improving knowledge regarding modern farming practices. Di Falco et al. (2012) found that farmers with better access to credit, along with information about the climate and information on agricultural extension, are more likely to adapt. More extensively, Di Falco and Veronesi (2013) found that better extension services along with climate information services increase the likelihood of adaptation strategies, echoing similar findings by Shiferaw and Holden (1998), Bekele and Drake (2003); Anley and Bogale (2007), Tesfaye and Brouwer (2012). In a more precise way, Deressa et al. (2008) found that the access of climate information on temperature and precipitation and credit sources increases the probability of adopting different crop varieties, soil conservation, changing planting dates and using irrigation.

\section{Study area}

The State of Bihar falls under tropical to a subtropical region where the temperature goes high and mild humidity, rainfall range between medium to high and heavy winter. The river Ganges divides the total geographic area, about 94,200 square km, into two parts, the north and the south Bihar. The States divided into three sub-agro-climatic zones (North West Alluvial Plains, North East Alluvial Plains and South Bihar Alluvial Plains) of the Middle Gangetic plains of India and the surveyed districts fall in all three sub-agro-climatic zones. The natural precipitation varies from 990 to $1,700 \mathrm{~mm}$. Most of the rain is received from July to September. The irony of the situation is that even though the quantum of rainfall is too high and a state is so rich in water bodies, it also suffers from severe droughts that intrinsically lead to famine. Bihar is India's most flood-prone state, with $76 \%$ of the population, in the north Bihar living under the flood threat. While the conditions are already experiencing a decreasing volume of rainfall, rainy days and increasing temperature (Giri, 2015), climate change is likely to worsen the problem with highly uneven and erratic rainfall floods and severe droughts. The study area has several initiatives for an agricultural extension such as Krishi Vigyan Kendra (KVK)-Agricultural Science Center) and Agricultural Technology Management Agency (ATMA). The agricultural officers and other professionals in these departments are responsible for knowledge transfer to farm households on-farm technologies and farming practices.

\section{Sampling and methodology}

The data collection was self-administered and approached farmers from all land size and ownership (owned or rented) groups. The structured questionnaire has been broadly discussed with the farmer to maintain consistency in responses and data collection. The structured questionnaire was developed to collect the farm household level information that includes socio-economic, Climate Information, agricultural extension services and adaptation strategies used by farm households to cope with climate change. The source of climate information and agricultural extension and adaptation strategies considered in particular question based on the pilot survey conducted before the final data collection and review of existing literature (Bradshaw et al., 2004; Maddison, 2007; Deressa et al., 2008; Below et al., 2012; Di Falco and Veronesi, 2013; Di Falco and Veronesi, 2013; Smithers, 1997; Roncoli et al., 2002; Hansen et al., 2004; Thomas et al., 2007). The farm households make their adaptation choices in Kharif and Rabi season among different adaptation strategies listed in Table 1. The strategies have been identified through an initial assessment of agricultural practices before the final survey and successfully captured the capital-intensive, laborintensive and knowledge-intensive techniques. Table 1 provides detail information about the variables for which data was collected. 


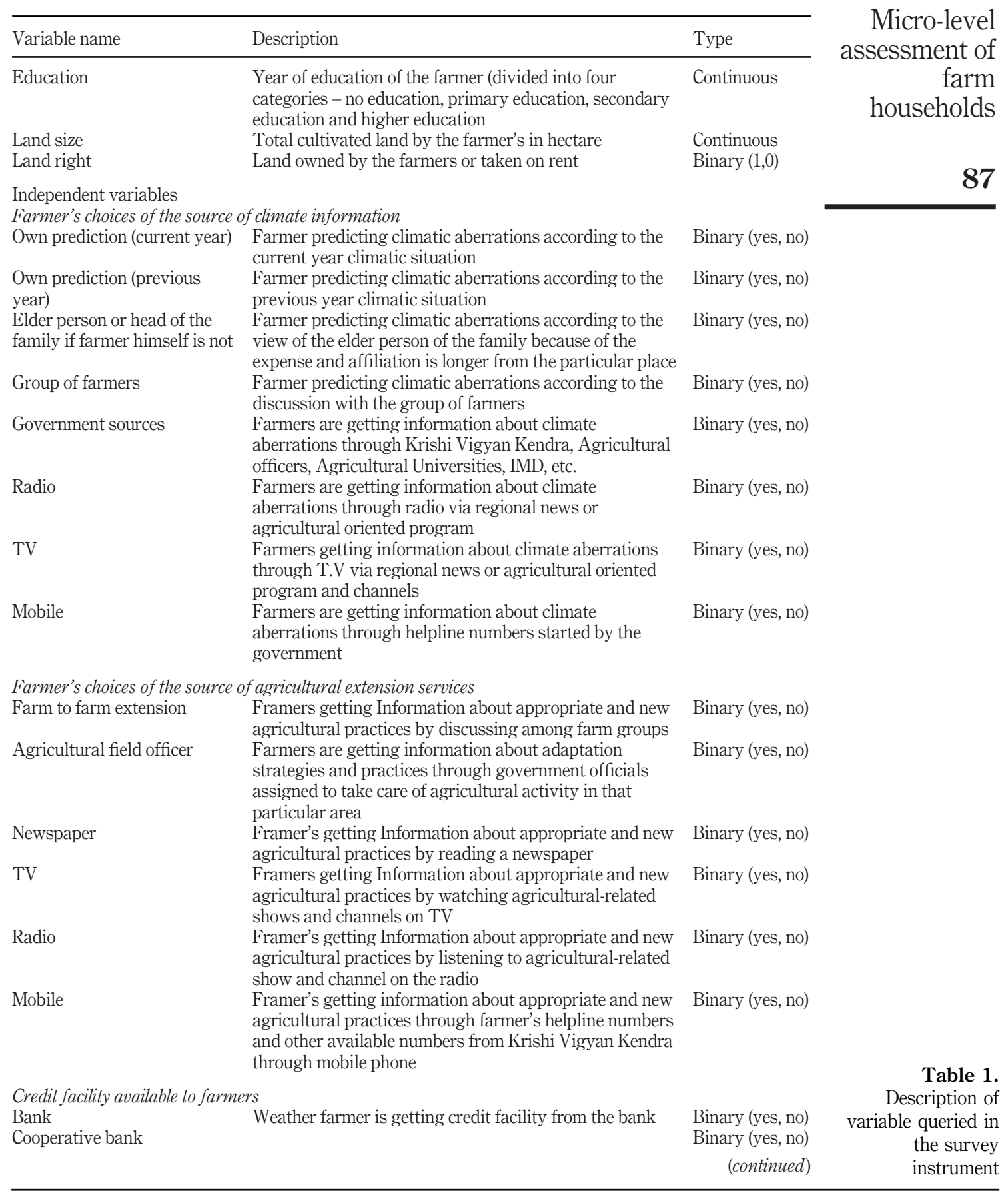




\section{EFCC}

2,2

\begin{tabular}{|c|c|c|}
\hline Variable name & Description & Type \\
\hline & $\begin{array}{l}\text { Weather farmer is getting credit facility from a } \\
\text { cooperative bank }\end{array}$ & \\
\hline Informal money lenders & $\begin{array}{l}\text { A farmer was taking a loan from local money lenders on } \\
\text { interest for agricultural activity }\end{array}$ & Binary (yes, no) \\
\hline NGO & $\begin{array}{l}\text { Farmers are getting credit facilities for their agricultural } \\
\text { activity from NGOs engaged in the same activity }\end{array}$ & Binary (yes, no) \\
\hline A problem in availing of loans & $\begin{array}{l}\text { Farm households reporting whether they faced problems } \\
\text { in availing loans from banks, cooperative banks and } \\
\text { NGOs }\end{array}$ & Binary (yes, no) \\
\hline \multicolumn{3}{|l|}{ Dependent variables } \\
\hline \multicolumn{3}{|c|}{ Adaptation strategies adopted by farm households } \\
\hline Changing crop varieties & $\begin{array}{l}\text { Planting different crops, drought-resistant varieties, } \\
\text { high-yield verities, water-sensitive crops and short- } \\
\text { duration varieties }\end{array}$ & Binary (yes, no) \\
\hline $\begin{array}{l}\text { Changing land under } \\
\text { cultivation }\end{array}$ & Land rotation or altering the area under cultivation & Binary (yes, no) \\
\hline Irrigation & $\begin{array}{l}\text { Increase/decrease the intensity of irrigation to overcome } \\
\text { shortage or excess rainfall. Using tube well, water pump, } \\
\text { etc. }\end{array}$ & Binary (yes, no) \\
\hline Soil conservation & For maintaining soil fertility-like zero-tilling, etc. & Binary (yes, no) \\
\hline Water conservation & Rainwater harvesting, building tanks or water reservoirs & Binary (yes, no) \\
\hline Crop insurance & $\begin{array}{l}\text { Insure crops to overcome crop losses due to climatic } \\
\text { disturbances }\end{array}$ & Binary (yes, no) \\
\hline Migration & $\begin{array}{l}\text { Migrating to the urban area to diversify their livelihood } \\
\text { options }\end{array}$ & Binary (yes, no) \\
\hline Farm to non-farm activities & $\begin{array}{l}\text { Changing land from farm to non-farm activities mainly in } \\
\text { non-climate sensitive activities }\end{array}$ & Binary (yes, no) \\
\hline Leasing land & Leasing land for other non-farm activities & Binary (yes, no) \\
\hline Planting horticulture crop & $\begin{array}{l}\text { Planting fruits such as mango, litchi, banana and guava } \\
\text { and nuts, seeds, herbs, sprouts, mushrooms, flowers, } \\
\text { seaweeds and non-food crops such as grass and } \\
\text { ornamental trees and plants }\end{array}$ & Binary (yes, no) \\
\hline Planting vegetables & $\begin{array}{l}\text { Planting vegetables such as potato, brinjal/eggplant, } \\
\text { cauliflower, cabbage, tomatoes and chili }\end{array}$ & Binary (yes, no) \\
\hline
\end{tabular}

Table 1.

88

Farm households reporting whether they faced problem in availing loans from banks, cooperative banks and

Dependent variables NGOs
Weather farmer is getting credit facility from a

A farmer was taking a loan from local money lenders on interest for agricultural activity

Farmers are getting credit facilities for their agricultural

\section{farm households}

high-yield verities, water-sensitive crops and shortduration varieties

Increase/decrease the intensity of irrigation to overcome shortage or excess rainfall. Using tube well, water pump, For maintaining soil fertility-like zero-tilling, etc.

Rainwater harvesting, building tanks or water reservoirs Insure crops to overcome crop losses due to climatic disturbances

Migrating to the urban area to diversify their livelihood options non-climate sensitive activities

Leasing land for other non-farm activities

Planting fruits such as mango, litchi, banana and guava and nuts, seeds, herbs, sprouts, mushrooms, flowers, seaweeds and non-food crops such as grass and Planting vegetables such as potato, brinjal/eggplant, cauliflower, cabbage, tomatoes and chili

The study has been conducted in the seven districts of India's Bihar state and among these districts, 72 villages were randomly selected for the survey. The distance from the district headquarters has been considered for the selection of the village. The villages close to district headquarter (within $10 \mathrm{~km}$ ) might have easy market access and institutional arrangements for agricultural support and vice versa (more than 10) subject to the districts' size. From 72 villages, we have surveyed randomly selected 735 households, but at the final stage, the data from 700 farm households were found for statistical analysis based on completeness and consistency. We tried to capture all land-sized groups such as marginal, medium, small and large - the farm household-related preliminary data collected from the village head.

We used descriptive statistics and statistical inference to analyze the climate information, an agricultural extension of the surveyed household. We use the logit model to assess the role of socio-economic characteristics on adaptation strategies. The logistic regression model is given by Greene (2017): 


$$
\log \left(\frac{P_{i}}{1-P_{i}}\right)=\log \left(P_{i}\right)=\beta_{0}+\beta_{i} X_{i}
$$

Micro-level assessment of

where $P_{i}$ is the probability of adopting particular adaptation strategies from the set of given adaptation strategies, $X_{i}$ is an independent variable. Therefore, the parameter $\beta_{i}$ provides the log with odds for the dependent variable and $\beta_{O}$ is a constant. The odds ratio is the probability of an event happening related to not happening.

\section{farm \\ households}

$$
\frac{P_{i}}{1-P_{i}}=\exp \left(\beta_{0}+\beta_{i} X_{i}\right)
$$

\section{Results and discussion}

\subsection{Climate information sources}

This study identifies 10 possible mediums through which farmers in the chosen districts of Bihar gather information on climate (Figure 1, Panel A). The respondents were asked, "How do they predict changes in future climate conditions and what are the main sources through which they gather climate information?" The respondents could choose the information they feel are important and commonly use to collect local climate info. The choices are not mutually exclusive, which means that each respondent can choose more than one source.

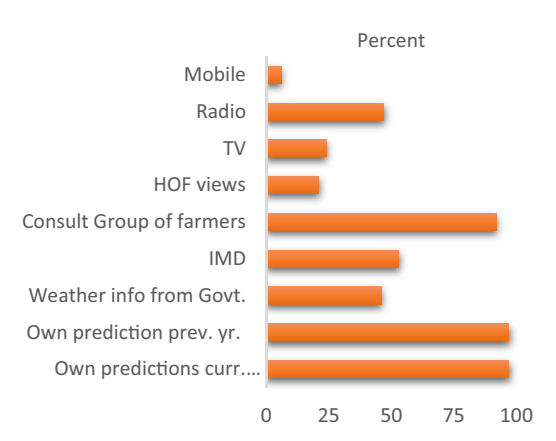

(a)

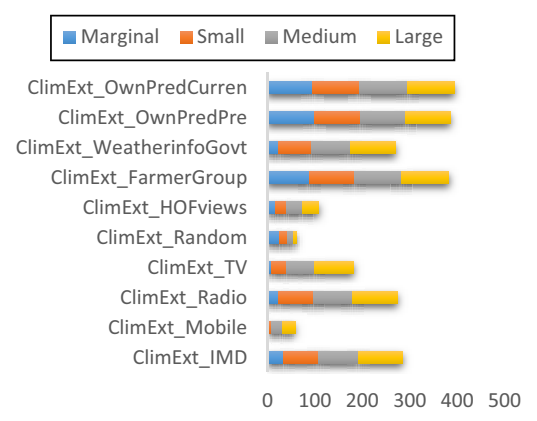

(c)

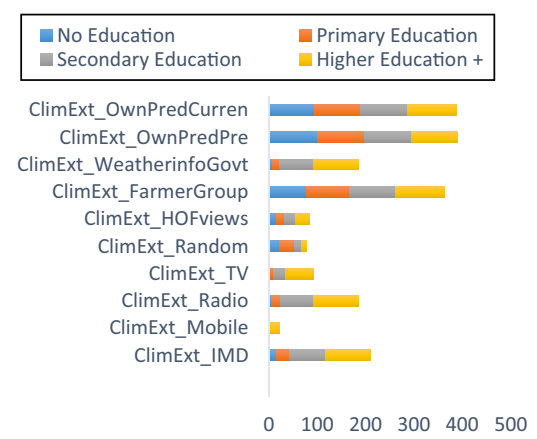

(b)

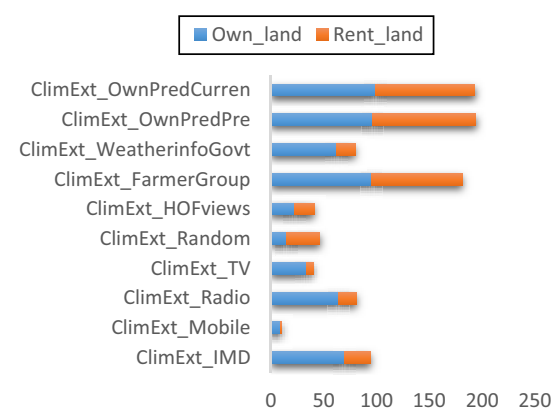

(d)
Figure 1.

Sources of climate information and role of education, land size and land rights 
EFCC

2,2

90

The most crucial channel through which farmers predict future climate is their prediction based on current and previous years' climate conditions followed by farmers $(92 \%$ of farm households). Climate information from local weather (53\%) stations and information from government sources $(46 \%)$ are other important sources. Another critical source of climate information is radio $(47 \%)$ and television $(24 \%)$. Views of the household head also hold another useful information source (21\%) and information through cellular phones $(6 \%)$. The spit of institutional effect has increased mobile use in the rural area, especially for agricultural business purposes, but barely used for climate information to alter agricultural practices.

From the above results, it is evident that farmers are mostly dependent on their mental capacity as an important source of climate information and consultation with fellow farmers. Social relations and community participation in exchanging ideas are perceived as more reliable. Although weather stations and the government's role in providing climate information are limited in this study, policy actions can reduce the uncertainty in farmer's predictions and help in efficient adaptation. The importance of household members' views, especially household heads, signifies personal relationships in climate forecasting. In rural areas, radio serves to be a critical source of entertainment and information, as rural electrification is still a crucial issue in villages. Therefore, using television as a source of climate information has a limited scope. The results show that the farmers in the study area are not using mobiles phone to get climate information due to the lack of awareness and their education level that restrict their understanding of the efficient use of mobile phones for agriculture.

The role of education, land size and land rights can be seen in Figure 1. The result shows that farmers from all education groups largely depend on their experience from the current and previous years and discussion among farmers for climate prediction. Simultaneously, highly educated farmers are also accessing T.V., Radio, mobile and government sources for climate information (Figure 1, Panel A). The land size and land rights play an essential role in accessing more reliable sources such as T.V., Radio, mobile and government sources. The result shows that higher educated farmers depend on these sources.

\subsection{Agriculture extension and credit sources}

To assess and identify the extension services accessible for the farmers in the study area, they were asked to choose the extension options based on how they use such services for their farm management. The extension services were distinctly divided between sources of agricultural knowledge and sources of credit. The farmers were asked to choose between the different sources of agricultural extension and credit. The choices reported by the are not mutually exclusive, implying they revealed for the possible options which they usually use, not the only option.

For this study, farmers enquired upon their extension services choices, which they often cater to for taking farm decisions and adaptations. The farm extension options assessed in this study are farmer's own experience, consult other farmers (farmer to farmer extension services), consult agricultural officers, Newspaper, T.V., Radio and Mobile.

The results of the study show that farmers are mostly dependent on their own experiences ( $97 \%, 680$ respondents) and farmer to farmer extension (97\%, 680 respondents) for deciding on-farm management (Figure 2, Panel A). From the results, farmers have more confidence in information gained from their past experiences and knowledge from their fellow farmers. Farmers often follow the "learning by doing" approach by learning from their past farm management experiences. In farmer-to-farmer extension, farmers habitually try to observe and copy farm activities of fellow farmers, including adopting technological 


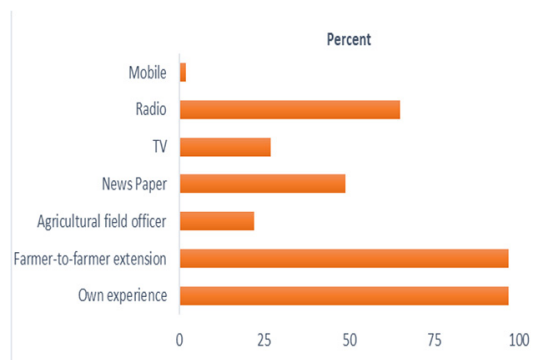

(a)

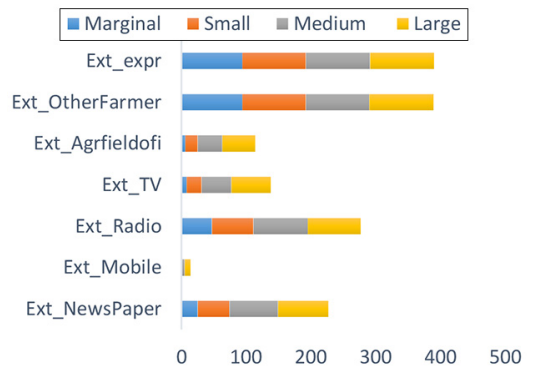

(c)

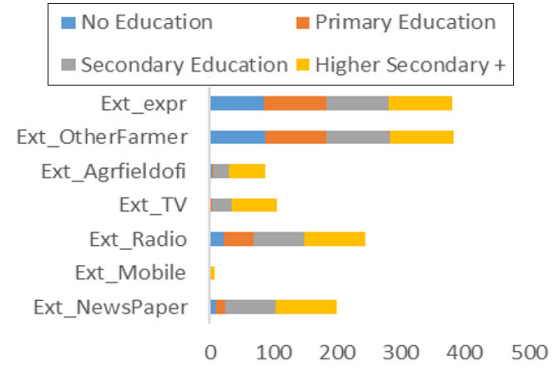

(b)

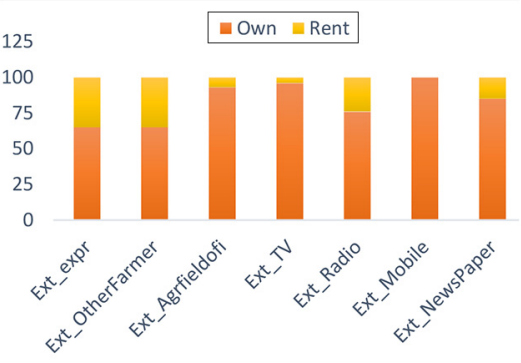

(d)
Micro-level
assessment of
farm
households

91

Figure 2.

Sources of

agricultural extension services and role of education, land size and land right

adaptation. In this way, farmers proceed to self-perfection, enabling them to take up minor innovations independently. Here, the importance of farmers' socio-economic conditions as individual agents and the social relationships they share with society cannot ignore. Therefore, it is also critical to identify the main socio-economic factors that augment farmers' behavioral attributes for personal decision-making. The second and third most crucial agricultural extension source is information through radio $(65 \%, 454$ respondents) and newspaper $(49 \%, 341$ respondents). Agricultural field officers have limited reach in providing farm extension ( $22 \%, 152$ respondents). The influence of agricultural field officers in the delivery of extension services seems limited in the study region. Agricultural field officers in the study region must arrange for the supply of farm inputs such as seeds and fertilizers by developing direct contact with farmers. Also, they organize training camps and field days and manage the distribution of Soil Health Cards. It is essential to assess here that despite these arrangements for farm management, the farmers have not benefited from learning by instructions. Only 27\% (190 respondents) and 2\% (15 respondents) of surveyed farmers use television and cellular devices as agricultural extension sources.

The role of education, land size and land rights can be seen in Figure 3. The results show that the traditional extension sources such as own prediction from current and previous year experiences are most common among all education classes. However, the access of agricultural officers, knowledge from T.V., radio, mobile and newspaper highly depend on farmers' education level. It means that more educated farmers are more intended toward these sources. The land size denoted as farm holding size in this study has also been analyzed to see their significance in accessing agricultural extension services. The land size determines the farming community's interest in adopting better farming practices and enhancing their ability to adapt. The results show that large land-sized farm households are consulting agricultural field officers to improve their farming practices to cope with climate 


\section{EFCC}

2,2

92

Figure 3.

Access to credit sources in the study area accesses by farmers

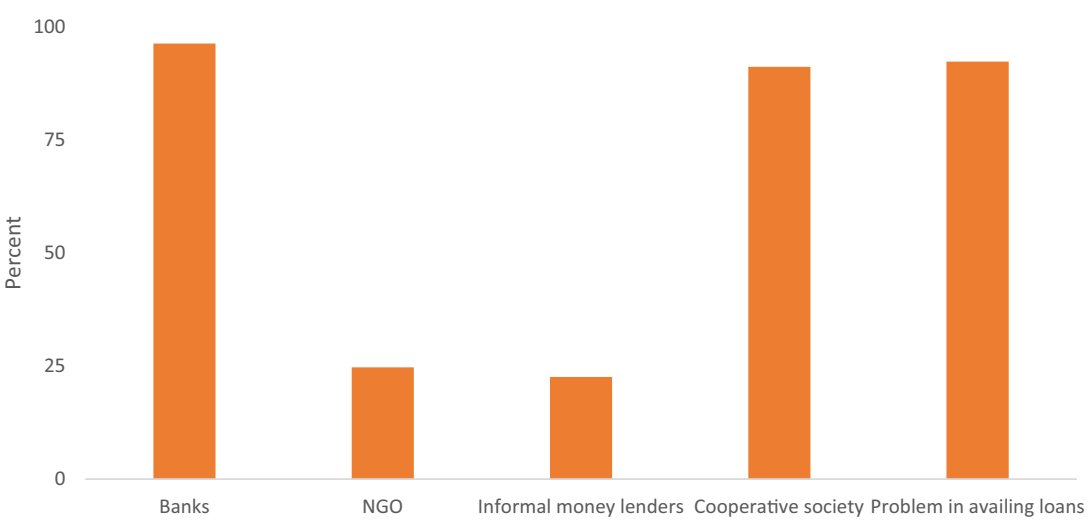

change. The large land holding farmers are also getting extension information through T.V., mobile and newspaper, followed by the medium-size farmer. The maximum number of marginal and medium-scale farmers depends on self-experience, farm to farm extension and radio as extension services. The marginal and small farmers have less awareness level but are timelessly motivated because they are left with less surplus production to sell after family consumption.

Along with land size, this study has found land ownership (Panel D) also determines the interest to assess agricultural extension services through all means. Our findings are in line with Gbetibouo (2009), who pointed out that secured positive incentives from farm investment to cope with climate change are high when the land ownership belongs to the farmer. For instance, secure land ownership increases the likelihood of the adoption of conservation technologies. Access to credit often increases the possibility of adaptation. Poverty or lack of financial resources causes severe impediments to adjustments to climate change. For credit extension, farmers were asked to answer the question, "Which credit sources do you opt for meeting the financial requirement for farming?" Also, farmers were asked whether they face any problem in availing of loans. This study tried to assess the different credit sources which the farm household accessed. Farmers were asked to list out their choices on sources of credit, i.e. banks, informal money lenders, co-operative societies and NGOs (Figure 3).

As per the results, about $96 \%$ of the surveyed farmers ( 674 respondents) avail loans from banks, $91 \%$ (638 respondents) avail loans from co-operative society, 25\% (173 respondents) from NGO and 23\% (158 respondents) from informal money lenders and about 25\% from NGOs (173 respondents). The three primary sources of credit in Bihar are commercial banks, regional banks and co-operative banks. Co-operative societies in the form of primary Agricultural Credit Societies (PACS) are the prominent agricultural credit source in the state. Although most of the surveyed farmers take loans from formal lending institutions, credit availability is still a significant issue for Bihar farmers. About $92 \%$ of the surveyed farmers reported problems in availing loans. The main issues farmers face in availing loans are an inappropriate attitude of bankers, stringent security norms and high-interest rates. Issues in availing loans from banks and co-operative society force them to take loans from informal credit sources such as agricultural and professional money lenders, relatives and friends, etc. The farmers are usually forced to accept the higher interest from informal sources due to the absence of formal credit sources that affect farming households' adaptive capacity or decisions, especially small-sized farmers. Credit availability and crop insurance have 
positive relations with altered agricultural practices to respond to climate shocks among Indian farmers as they are mostly small to medium scale farmers.

\subsection{Role of climate information in adaptation strategies}

Information on temperature and rainfall has a significant and positive impact on using different adaptation strategies. The relationship between assessing the additional climate information and adaptation decision is explained in Tables 2 and 3.

The results show that there is a positive relationship between climate information and adaptation strategies. Adopting the different crop varieties negatively correlates with those drawing perceptions regarding climate change through personal experience based on current and previous year climatic situations and the family's elder. The aged members of the family may have emotional attachments with their traditional agricultural system and they push to adopt the same. The study shows that the changing crop varieties have a significant positive relation with getting information about climate change from the discussion among farmers, elders or household heads, government sources and radio in both agricultural seasons. The elders or household head experience helps farmers understand the short-term climate variability in particular agriculture seasons and decide the appropriate crop varieties. The government sources and radio provides climate bulletin from time to time and those who access information from the government determine the crop varieties more appropriately. Changing land area has a significant positive relation with older household members' suggestions and discussion among farmers in Rabi season. Increasing irrigation has a significant positive association with more senior household members in Rabi for temperature and rainfall changes and Kharif for temperature changes. Discussion among farmers and radio as information is also found significant in increasing irrigation in both seasons. Changing land area and irrigation is the traditional management system and older members may appreciate farmers adopting these strategies. This study shows that the likelihood of adopting knowledge-intensive adaptation strategies such as soil conservation water conservation is high if the farmer is accessing government sources, T.V., radio and mobile phones. These are mostly technology-driven information sources, i.e. television, radio and mobile. The implementation of conservation technology needs a proper understanding of the scientific package of the particular strategies. The agricultural officers help them build their capacity to understand the specific conservation strategies' scientific process. The study found that climate information through mobile phones is crucial for appropriate and timely adaptation strategies to cope with climate change and manage the risk. The paper demonstrates that climate information delivered using mobile phones is useful to farmers. Farmers accessing information from these sources are more likely to predict the climate and adopt practices accordingly. Other strategies such as planting horticulture and vegetables are also positively related to government sources, television, radio and mobile. Farm households sometimes chose to cultivate these crops if they correctly perceived variability in climatic factors that could not grow other staple crops. This study has found that getting information on climate variability on time from authentic sources is more likely to change their agricultural practices and adopt strategies to cope with climate change.

\subsection{Role of agricultural extension services in adaptation strategies}

The better flow of knowledge through extension services generates a dissimilar effect on farmers' well-being and reduces asymmetric information. These services enable farmers to take early responses to reduce the risk and concurrently the cost of adaptation. The relationship between agricultural extension services and adaptation strategies given in Tables 4 and 5 .
Micro-level assessment of farm households 
EFCC

2,2

94
Table 2.

Logistic regression model of adaptation strategies and climate informationadaptation-Rabirainfall/temperature

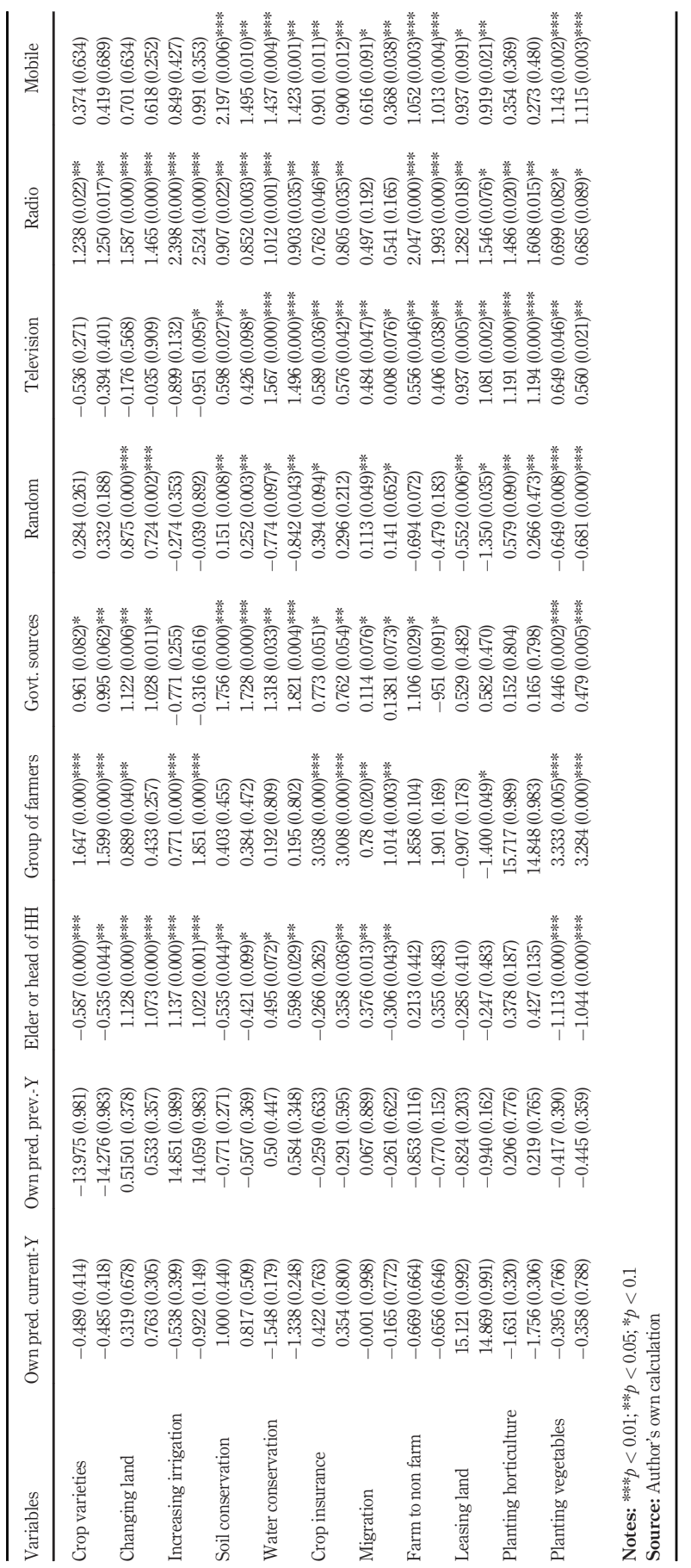




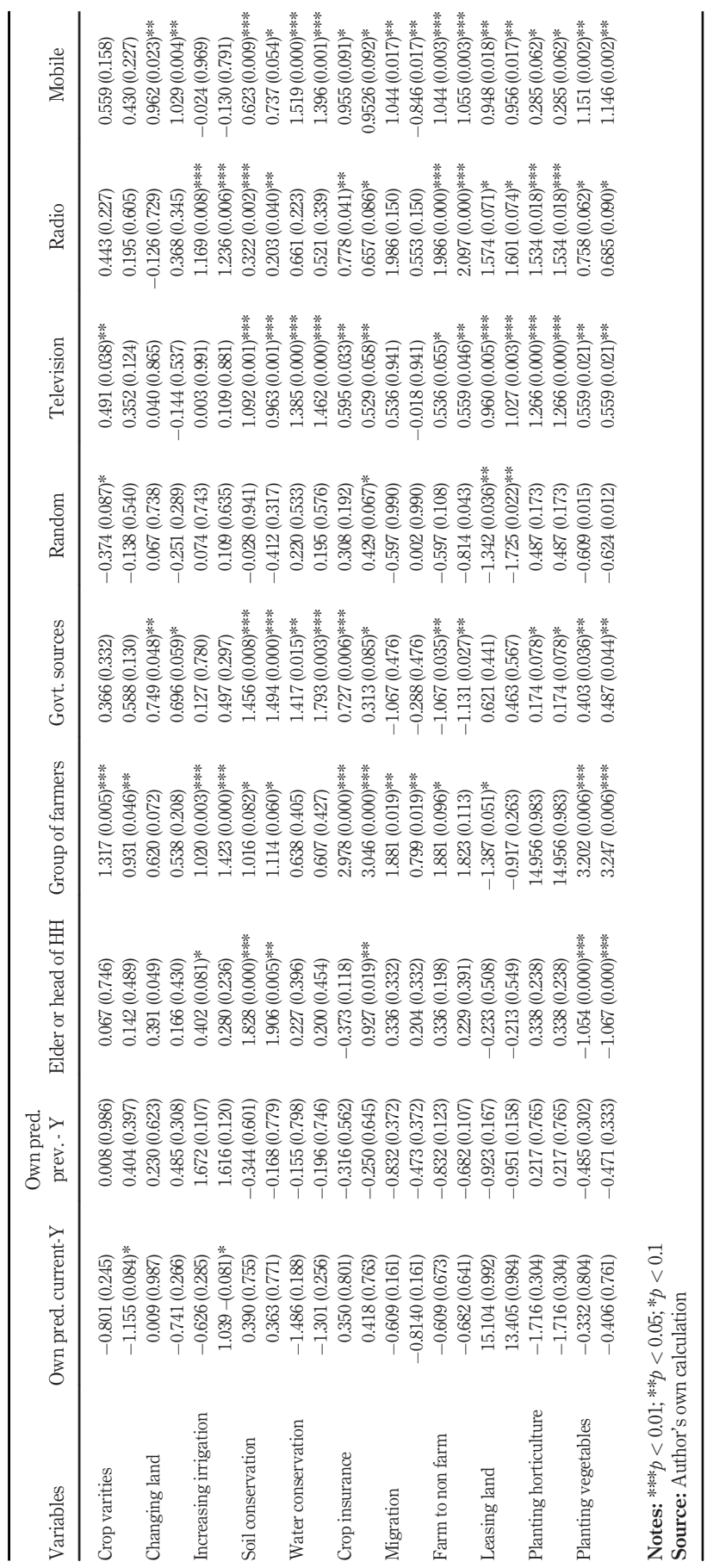

Micro-level
assessment of
farm
households

95

Table 3.

Logistic regression model of adaptation strategies and climate informationadaptation-Khariftemperature/rainfall 


\section{EFCC}

2,2

96

Table 4.

Logistic regression model of adaptation strategies and extension servicesadaptation-Rabitemperature/rainfall

\begin{tabular}{|c|c|c|c|c|c|c|c|}
\hline Variables & $\begin{array}{l}\text { Personal } \\
\text { Experience }\end{array}$ & $\begin{array}{c}\text { Farm to } \\
\text { Farm }\end{array}$ & Agro-field officer & Newspaper & Television & Radio & Mobile \\
\hline \multirow[t]{4}{*}{ Crop varieties } & 2.139 & 0.351 & -0.303 & 2.396 & 1.092 & 10.372 & 0.935 \\
\hline & $(0.009) * * *$ & -0.654 & -0.568 & $(0.002)^{* * * *}$ & $(0.000)^{* * *}$ & -0.474 & $(0.000)^{* * *}$ \\
\hline & 2.377 & 0.474 & -0.255 & 2.420 & 1.126 & 10.367 & 0.888 \\
\hline & $(0.007)^{* * * *}$ & -0.555 & -0.629 & $(0.002)^{* * * *}$ & $(0.000)^{* * *}$ & -0.979 & $(0.005)^{* * *}$ \\
\hline \multirow[t]{4}{*}{ Changing land } & 13.655 & 14.622 & 0.254 & 0.474 & 1.101 & 0.769 & 1.406 \\
\hline & -0.982 & -0.982 & -0.437 & -0.134 & $(0.000)^{* * *}$ & -0.474 & $(0.000)^{* * *}$ \\
\hline & 1.369 & 1.967 & 0.235 & 0.576 & 1.101 & 12.909 & 1.303 \\
\hline & -0.261 & -0.119 & -0.475 & $(0.069)^{*}$ & $(0.000)^{* * *}$ & -0.976 & $(0.000) * * * *$ \\
\hline Increasing & 2.713 & 0.893 & 0.328 & 2.713 & 1.165 & 11.014 & 0.310 \\
\hline \multirow[t]{3}{*}{ Irrigation } & $(0.001)^{* * *}$ & -0.246 & -0.627 & $(0.011)^{* *}$ & $(0.000)^{* * *}$ & -0.989 & -0.4 \\
\hline & 2.827 & 1.006 & 0.573 & 1.939 & 1.032 & 11.497 & 0.094 \\
\hline & -0.001 & -0.194 & -0.396 & $(0.014)^{* *}$ & $(0.001)^{* * * * *}$ & -0.988 & -0.79 \\
\hline \multirow[t]{4}{*}{ Soil conservation } & 11.839 & 13.269 & 0.724 & 1.266 & 0.932 & 14.455 & 2.172 \\
\hline & -0.984 & -0.983 & $(0.018)^{* *}$ & $(0.000)^{* * * *}$ & $(0.001)^{* * * *}$ & -0.988 & $(0.000) * * *$ \\
\hline & 12.735 & 14.200 & 0.490 & 1.142 & 0.944 & 0.985 & 2.205 \\
\hline & -0.989 & -0.988 & $(0.088)^{*}$ & $(0.000) * * *$ & $(0.001)^{* * *}$ & -0.358 & $(0.000) * * *$ \\
\hline \multirow[t]{4}{*}{ Water conservation } & 10.449 & 11.175 & 1.013 & 1.529 & 1.137 & 1.642 & 1.256 \\
\hline & -0.986 & -0.985 & $(0.000)^{* * *}$ & $(0.000)^{* * *}$ & $(0.011)^{* *}$ & $(0.045)^{*}$ & $(0.003)^{* * *}$ \\
\hline & 11.487 & 12.199 & 1.055 & 1.616 & 0.981 & 1.497 & 1.302 \\
\hline & -0.991 & -0.99 & $(0.000)^{* * *}$ & $(0.000) * * *$ & $(0.023) * *$ & $(0.066)^{*}$ & $(0.002) * * *$ \\
\hline \multirow[t]{4}{*}{ Crop insurance } & 14.489 & 15.290 & 0.281 & 1.523 & 1.053 & 15.628 & 1.270 \\
\hline & -0.991 & -0.99 & -0.381 & $(0.000)^{* * *}$ & $(0.000)^{* * *}$ & -0.996 & $(0.000) * * *$ \\
\hline & 14.488 & 15.230 & 0.419 & 1.522 & 1.086 & 15.593 & 1.183 \\
\hline & -0.991 & -0.99 & -0.192 & $(0.000)^{* * *}$ & $(0.000)^{* * *}$ & -0.996 & $(0.000)^{* * *}$ \\
\hline \multirow[t]{4}{*}{ Migration } & 14.768 & 14.694 & 0.501 & 0.503 & 0.510 & 0.408 & 0.258 \\
\hline & -0.979 & -0.979 & $(0.075)^{* * *}$ & $(0.062)^{*}$ & $(0.012)^{* *}$ & -0.608 & -0.258 \\
\hline & 2.044 & 1.045 & _0.440999 & 0.596 & 0.408 & 0.665 & 0.336 \\
\hline & -0.023 & -0.195 & -0.118 & $(0.035)^{* *}$ & $(0.043)^{* *}$ & -0.398 & -0.148 \\
\hline Farm to non & 12.366 & 12.209 & 1.145 & 0.506 & 1.385 & 1.879 & -0.340 \\
\hline \multirow[t]{3}{*}{ Farm } & -0.989 & -0.989 & $(0.000)^{* * *}$ & $(0.014)^{* *}$ & $(0.000)^{* * *}$ & $(0.004)^{* * *}$ & -0.314 \\
\hline & 13.333 & 13.248 & 1.157 & 0.480 & 1.365 & 1.778 & -0.179 \\
\hline & -0.993 & -0.993 & $(0.000)^{* * *}$ & $(0.023)^{* *}$ & $(0.000)^{* * *}$ & $(0.006)^{* * *}$ & -0.59 \\
\hline Leasing & 12.318 & 12.744 & 0.814 & 0.908 & 0.731 & 1.616 & 0.923 \\
\hline \multirow[t]{3}{*}{ Land } & -0.994 & -0.994 & $(0.023)^{* *}$ & $(0.021)^{* *}$ & -0.178 & $(0.005)^{* * *}$ & $(0.089)^{*}$ \\
\hline & 12.357 & 13.054 & 0.775 & 0.893 & 0.893 & 1.698 & 1.202 \\
\hline & -0.996 & -0.996 & $(0.032)^{* * * *}$ & $(0.025)^{* *}$ & $(0.075)^{*}$ & $(0.004)^{* * * *}$ & $(0.049)^{* *}$ \\
\hline Planting & 12.302 & 12.262 & 0.232 & 1.444 & 1.330 & 1.196 & 0.083 \\
\hline \multirow[t]{3}{*}{ Horticulture } & -0.991 & -0.992 & $(0.075)^{*}$ & $(0.000) * * *$ & $(0.003) * * *$ & $(0.036)^{* * *}$ & $(0.030)^{* *}$ \\
\hline & 12.246 & 12.207 & 0.189 & 1.607 & 1.265 & 1.083 & 0.086 \\
\hline & -0.991 & -0.991 & $(0.056)^{*}$ & $(0.000)^{* * *}$ & $(0.005)^{* * *}$ & $(0.056)^{*}$ & $(0.029) * *$ \\
\hline \multirow[t]{4}{*}{ Planting vegetables } & 1.097 & 1.071 & 0.228 & 0.993 & 0.818 & 0.751 & 0.082 \\
\hline & -0.338 & -0.398 & $(0.064)^{*}$ & $(0.000) * * *$ & $(0.000) * * *$ & $(0.194))$ & $(0.024)^{* *}$ \\
\hline & 1.074 & 1.049 & 0.346 & 1.074 & 0.867 & 0.792 & 0.079 \\
\hline & -0.4 & -0.411 & $(0.074)^{*}$ & $(0.000)^{* * *}$ & $(0.000)^{* * *}$ & -0.171 & $(0.034)^{* *}$ \\
\hline
\end{tabular}

Notes: $* * * p<0.01 ; * * p<0.05 ; *^{*} p<0.1$

Source: Author's own calculation 


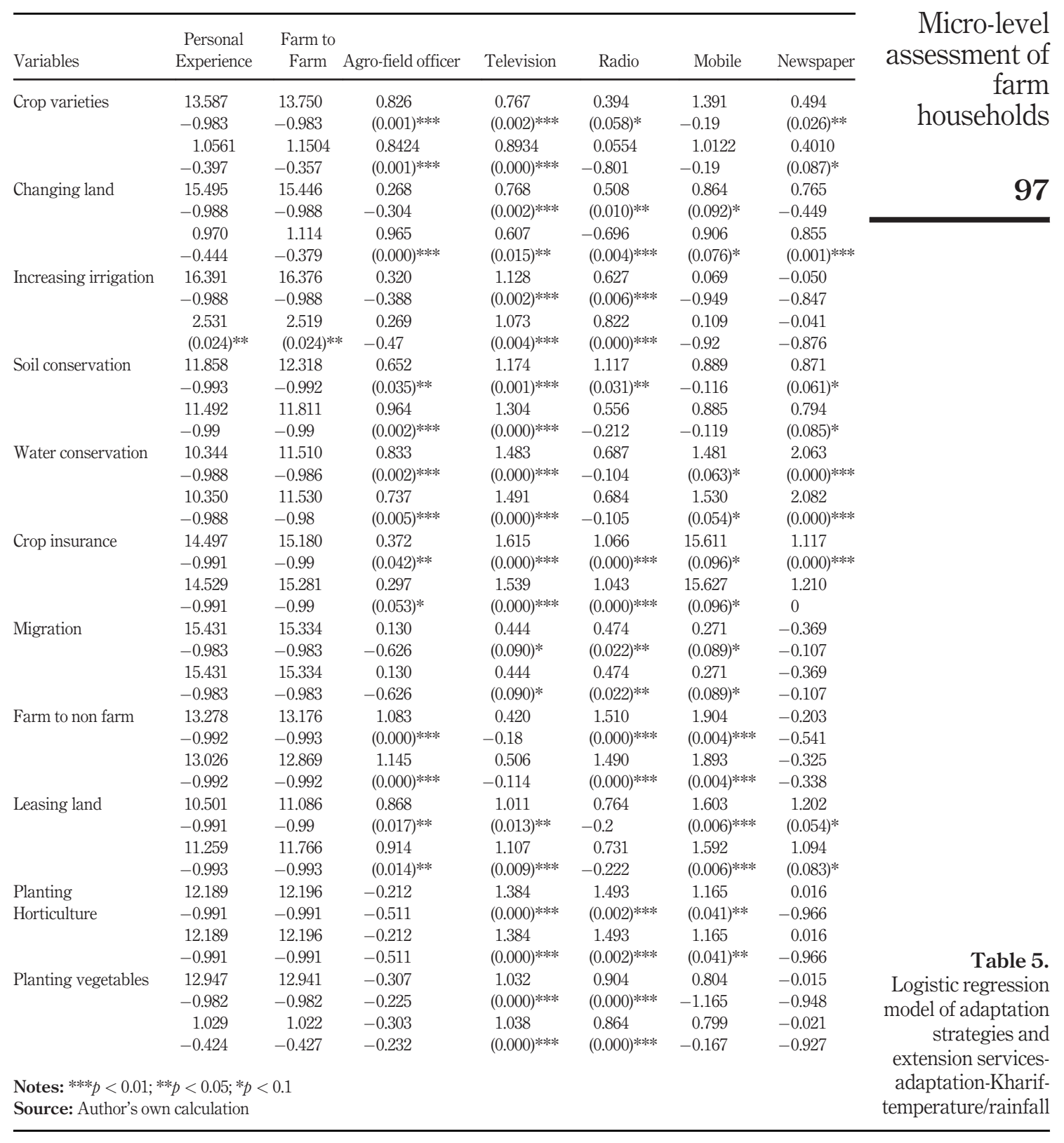


EFCC

2,2

\section{8}

Potentially the extension services are always defined as the significant factor that can influence the adaptive capacity and enhance the adaption decision of farm households to cope with climate change (Maddison, 2007; Nhemachena and Hassan, 2007). The introduction and defusion of new technology depend on the useful information channel to accept the latest technology (Wozniak, 1984). The technological diffusion literature (Adesina and Baidu-Forson, 1995) hypothesized that the better exposure of information and technical skills through efficient extension services is positively related to adaptation. Our results align with the previous studies (Deressa et al., 2008; Keil et al., 2008), indicating a positive relationship between adaptation strategies and agricultural extension services, specifically with institutional arrangements and primary sources (Television, Radio, Mobile and Newspaper). The probability of adopting different crop varieties is significantly high if the farm household accessed T.V. newspaper and radio to enhance their agricultural knowledge. The government provides information about the different varieties such as flood and drought resilience through the agricultural specific program, which helps farmers get information about the suitable varieties. The farmers usually get information about crop varieties through these sources and agricultural officers increase confidence among farmers and provide assistance to harvest these crops. The likelihood of adaptation of changing land under cultivation increased if the information is accessed through an agricultural officer, television, newspaper in Kharif for temperature and rainfall changes. The agricultural officers usually help the farmer maintain their soil nutrition and rotate the land under cultivation. Increasing irrigation is the other important adaptation strategy which highly influenced by the institutional arrangements. The government provides subsidies through agricultural officers to water pumps to increase irrigation. Framers usually get information about these subsidies through newspapers and radio. The technological and knowledgeintensive strategies such as soil conservation and water conservation are positively correlated with the agricultural officer, Television, Radio, mobile and newspaper in Kharif for both temperature and rainfall changes. Educated farmers assess information about the scientific package of these strategies through the agricultural officer. The government helps them learn about conservative practices through KVK and primary sources. The institutional arrangements also increase the likelihood of crop insurance. This study has found a strong positive relationship between these arrangements and crop insurance. The government used primary sources to improve crop insurance awareness programs and compensate for crop loss through agricultural officers. The income diversification strategies such as leasing land and changing land from farm to non-farm activities are likely to increase in those who are assessing the information through television, radio, newspaper and mobile. Farmers usually get information about these incomes generating non-farm activity through these sources. The large farm landholders divert some of their lands for these activities - the likelihood of planting horticulture and vegetable increases if the farmers were getting assistance from institutional arrangements. The government also provides knowledge about horticultural crops through specialized agricultural programs on television and radio.

\section{Conclusion}

This study has conducted the micro-level assessment of different climate information sources and agricultural extension services used by the farm household in the study area. The results of this signify that farmers have more confidence in information gained from their past experiences and knowledge gained from their fellow-farmers on-farm management practices, representing the importance of collective actions. The other effective extension services are the radio and newspapers. The study finds the limited influence of 
agricultural field officers in enhancing learning benefits by instructions for the farmers. For credit sources, co-operative societies and banks are the most prominent finance sources in the study area. Despite this, farmers reported facing problems in availing loans due to bankers' wrong attitude, stringent security norms and high-interest rates.

The efficiency of extension services is crucial to articulate effective agricultural adaptation and mitigation approaches. The study tried to understand the importance of different extension options in farmers' processes to tackle risks from climatic incidences and other farm management decisions. The study identifies that both climate extension services and agricultural extension services complement the farming decisions of farmers. Therefore, policies in the delivery of extension services should prioritize the two extension types distinctly to enhance the efficacy of extension arrangements in climate change adaptation. One critical inference that the study draws is that the farmers rely more on their own experience and discussion with fellow farmers. The extension service providers need to recognize farmers and villagers as the extension system's main stakeholders by strengthening their social networks through active interactions and community engagements. Our results emphasize the acceleration in rural and agricultural investment to support information sources' channel to enhance households' ability to seasonal and appropriate adaptation decisions that affect the rural well-being. Therefore, policy-makers should extend and improve upon such services, ensuring that they reach small-scale subsistence farmers. Providing support to the most impoverished farmers is critically important, given that this group is the most vulnerable to long-term climate change and least equipped to make the changes needed to sustain their livelihoods in the face of the climate threat. Addressing these market imperfections, lack of access to information and credit and ensuring effective targeting requires strong leadership and government involvement in planning for adaptation and implementing measures to facilitate adaptation at the farm level. Farmers mainly rely on the farmer to farmer extension services and find information through television and radio useful if effectively provided. In a few years to come, mobile phones are likely to become a critical source of agriculture and climate extension services. Increased penetration of low-cost smartphones and decreasing mobile data prices have enhanced mobile phone usage in agricultural management. Digital literacy helps overcome the barriers of education constraints, information asymmetry and cost hurdles and strengthen smallholder farmers' adaptive capacity by establishing direct connections between farmers, state government, agricultural research organizations and extension and technology providers. Digital integration of agriculture actors (farmers) in the agriculture value chain can enhance agriculture management's efficiency and accuracy under climate change conditions by delivering accurate and real-time information for farmers' decision-making. To improve resilience to cope with climate change, there is a need to have more support from the public and private sector in terms of investment in capacity-building programs on anticipatory strategic decision-making. These investments will significantly increase the likelihood of the use of adaptation strategies of farm households. Designing policy aiming at capacity building on the farming system will potentially enhance the appropriate and on-time adaptation decision.

\section{References}

Adesina, A.A. and Baidu-Forson, J. (1995), "Farmers' perceptions and adoption of new agricultural technology: evidence from analysis in Burkina Faso and Guinea, West Africa", Agricultural Economics, Vol. 13 No. 1, pp. 1-9.

Adger, W.N., Huq, S. and Hulme, M. (2003), "Adaptation to climate change in the developing world", Progress in Development Studies, Vol. 3 No. 3, pp. 179-195.

Agrawal, A. (2008), "The role of local institutions in adaptation to climate change". 
EFCC

2,2

Agrawal, A. and Perrin, N. (2009), "Climate adaptation, local institutions and rural livelihoods", Adapting to Climate Change: Thresholds, Values, Governance, pp. 350-367.

Ajibade, L.T. and Shokemi, O.O. (2003), "Indigenous approach to weather forecasting in ASA LGA, Kwara State, Nigeria”, Indilinga African Journal of Indigenous Knowledge Systems, Vol. 2 No. 1, pp. 37-44.

Anley, Y. and Bogale, A. (2007), "adoption decision and use intensity of soil and water conservation measures by smallholder subsistence farmers in dedo district", Western Ethiopia, Vol. 302, pp. 289-302, doi: 10.1002/ldr.

Arbuckle, J.G., Morton, L.W. and Hobbs, J. (2015), "Understanding farmer perspectives on climate change adaptation and mitigation: the roles of trust in sources of climate information", Climate Change Beliefs, and Perceived Risk, doi: 10.1177/0013916513503832.

Bekele, W. and Drake, L. (2003), "Soil and water conser v ation decision beha v ior of subsistence farmers in the Eastern Highlands of Ethiopia: a case study of the Hunde-Lafto area”, Ecological Economics, Vol. 46 No. 3, pp. 437-451, doi: 10.1016/S0921-8009(03)00166-6.

Below, T.B., Mutabazi, K.D., Kirschke, D., Franke, C., Sieber, S., Siebert, R. and Tscherning, K. (2012), 'Can farmers' adaptation to climate change be explained by socio-economic household-level variables?", Global Environmental Change, Vol. 22 No. 1, pp. 223-235, doi: 10.1016/j. gloenvcha.2011.11.012.

Bradshaw, B.E.N., Dolan, H. and Smit, B. (2004), "farm-level adaptation to climatic variability and change: crop diversification in the Canadian prairies", Climatic Change, Vol. 67 No. 1, pp. 119-141.

Carswell, G. and Jones, S. (2004), "Introduction: environmental problems in the tropics: challenging the orthodoxies", Environment, Development and Rural Livelihoods, pp. 3-11.

Cooper, P.J.M., Dimes, J., Rao, K.P.C. and Shapiro, B. (2008), "Coping better with current climatic variability in the rain-fed farming systems of Sub-Saharan Africa: an essential first step in adapting to future climate change?", Agriculture, Ecosystems and Environment, Vol. 126 Nos 1/2, pp. 24-35, doi: 10.1016/j.agee.2008.01.007.

Deressa, T., Hassan, R.M. and Ringler, C. (2008), "Measuring ethiopian farmers' vulnerability to climate change across regional states [in amharic]: Measuring ethiopian farmers' vulnerability to climate change across regional states temesgen deressa”, (May 2014).

Di Falco, S. and Veronesi, M. (2013), "How can African agriculture adapt to climate change?", $A$ Counterfactual Analysis from Ethiopia, pp. 761-784.

Di Falco, S., Yesuf, M., Kohlin, G. and Ringler, C. (2012), "Estimating the impact of climate change on agriculture in low-income countries: household level evidence from the Nile Basin, Ethiopia”, Environmental and Resource Economics, Vol. 52 No. 4, pp. 457-478.

Dunne, A., Markey, A., Kinsella, J., Dunne, A., Markey, A. and Kinsella, J. (2019), "Examining the reach of public and private agricultural advisory services and farmers' perceptions of their quality: the case of county Laois in Ireland", The Journal of Agricultural Education and Extension, Vol. 8622, doi: 10.1080/1389224X.2019.1643746.

Eakin, H. (2005), "Institutional change, climate risk, and rural vulnerability: cases from Central Mexico", World Development, Vol. 33 No. 11, pp. 1923-1938.

Gbetibouo, G.A. (2009), "Understanding farmers' perceptions and adaptations to climate change and variability: the case of the Limpopo Basin, South Africa”, International Food Policy Research Institute, Vol. 849.

Greene, W.H. (2017), Econometric Analysis, 8th ed.

Giri, R.K. (2015), “issn: 2278-6252 study of bio-climatic indices over Bihar region issn: 2278-6252", International Journal of Advanced Research in Engineering and Applied Sciences, Vol. 4 No. 5, pp. 43-50.

Hammill, A. Matthew, R. and Mccarter, E. (2008), "Microfinance and climate change adaptation", Vol. 39 No. 4, pp. 113-122. 
Hansen, J. (2007), "Innovations in climate risk management: protecting and building rural livelihoods in a variable and changing climate 1", Vol. 4 No. 1, pp.1-38.

Hansen, J., Marx, S. and Weber, E. (2004), "The role of climate perceptions, expectations, and forecasts in farmer decision making".

IPCC (2014), "Summary for policymakers in: Climate Change 2014: Impacts, Adaptation, and Vulnerability. Part A: Global and Sectoral Aspects. Contribution of Working Group II to the Fifth Assessment Report of the Intergovernmental Panel on Climate Change ed C B Field et al.", Cambridge University Press, Cambridge, United Kingdom and New York, NY, USA, pp. 1-32.

Micro-level assessment of farm households

Isham, J. (2002), "The effect of social capital on fertiliser adoption: evidence from rural Tanzania", Journal of African Economies, Vol. 11 No. 1, pp. 39-60.

Keil, A., Zeller, M., Wida, A., Sanim, B. and Birner, R. (2008), "What determines farmers' resilience towards ENSO- related drought?”, Climatic Change, Vol. 86 No. 3-4, pp. 291-307, doi: 10.1007/ s10584-007-9326-4.

Mcleman, R., Mayo, ÆED., Strebeck, ÆEE. and Smit, ÆB. (2008), "Drought adaptation in rural Eastern Oklahoma in the 1930s: lessons for climate change adaptation research", Mitigation and Adaptation Strategies for Global Change, Vol. 13 No. 4, pp. 379-400, doi: 10.1007/s11027-0079118-1.

Maddison, D. (2007), "The perception of and adaptation to climate change in africa”, (August).

Nettle, R., Klerkx, L., Faure, G., Koutsouris, A., Nettle, R., Klerkx, L. and Governance, A.K. (2017), "Governance dynamics and the quest for coordination in pluralistic agricultural advisory systems", Vol. 8622, doi: 10.1080/1389224X.2017.1320638.

Nhemachena, C. and Hassan, R. (2007), "Micro-Level analysis of farmers' adaptation to climate change in Southern Africa micro-level analysis of farmers' adaptation to climate change in Southern africa charles nhemachena", Centre for Environmental Economics and Policy in Africa (CEEPA).

Pacey, A., Chambers, R. and Thrupp, L.A. (1989), Farmer First: Farmer Innovation and Agricultural Research, Intermediate Tecnology Publications.

Ragasa, C., Ulimwengu, J. and Randriamamonjy, J. (2016), "Factors affecting performance of agricultural extension: evidence from democratic republic of Congo factors affecting performance of agricultural extension: evidence from democratic republic of Congo", Journal of Agricultural Education and Extension, pp. 1-31, doi: 10.1080/1389224X.2015.1026363.

Ramborun, V., Facknath, S. and Lalljee, B. (2019), "Moving toward sustainable agriculture through a better understanding of farmer perceptions and attitudes to cope with climate change", The Journal of Agricultural Education and Extension, Vol. 26 No. 1, pp. 1-21, doi: 10.1080/ 1389224X.2019.1690012.

Roncoli, C., Ingram, K.T. and Kirshen, P. (2002), "Reading the rains: local knowledge and rainfall forecasting in Burkina Faso reading the rains: local knowledge and rainfall forecasting in Burkina Faso", Society and Natural Resources, Vol. 15 No. 5, doi: 10.1080/08941920252866774.

Shiferaw, B. and Holden, S.T. (1998), "Resource degradation and adoption of land conservation technologies in the ethiopian highlands: a case study in andit tid, North shewa”, Agricultural Economics, Vol. 18 No. 3.

Smithers, J. (1997), "Human adaptation climatic variability change and", Global Environmental Change, Vol. 7 No. 2, pp. 129-146.

Stern, N. and Stern, N.H. (2007), The Economics of Climate Change: The Stern Review, Cambridge University press.

Tesfaye, A. and Brouwer, R. (2012), "Testing participation constraints in contract design for sustainable soil conservation in Ethiopia”, Ecological Economics, Vol. 73, pp. 168-178, doi: 10.1016/j.ecolecon.2011.10.017.

Thomas, D.S.G., Twyman, C., Osbahr, H. and Hewitson, B. (2007), "Adapting to climate change and variability in Southern Africa: farmer responses to intra-seasonal precipitation trends 
EFCC

2,2

102

adaptation to climate change and variability: farmer responses to intra-seasonal precipitation trends in South Africa", Climatic Change, Vol. 83 No. 3, doi: 10.1007/s10584-006-9205-4.

Vogel, C. and O'Brien, K. (2006), "Who can eat information? Examining the effectiveness of seasonal climate forecasts and regional climate-risk management strategies", Climate Research, Vol. 33 No. 1, pp. 111-122.

Wozniak, G.D. (1984), “The adoption of interrelated innovations: a human capital approach", The Review of Economics and Statistics, pp. 70-79.

Ziervogel, G., Bharwani, S. and Downing, T.E. (2006), "Adapting to climate variability: pumpkins, people and policy”, Natural Resources Forum, Vol. 30 No. 4, doi: 10.1111/j.14778947.2006.00121.x.

Ziervogel, G., Bithell, M. and Washington, R. (2005), "Agent-based social simulation: a method for assessing the impact of seasonal climate forecast applications among smallholder farmers", Agricultural Systems, Vol. 83 No. 1, pp. 1-26, doi: 10.1016/j.agsy.2004.02.009.

\section{Further reading}

Africa, W. and Adesina, A.A. (1995), "Farmers' perceptions and adoption of new agricultural technology: evidence from analysis in Burkina Faso", Agricultural Economics, Vol. 13, pp. 1-9.

Al, T.E.T. (2017), "Addressing climate change impacts on agriculture and natural resources: barriers and priorities for land-grant universities in the northeastern United States", doi: 10.1175/WCASD-16-0106.1.

Di, S., Mahmud, F. and Gunnar, Y. (2012), "Estimating the impact of climate change on agriculture in low-income countries: household level evidence from the Nile basin", Ethiopia, pp. 457-478, doi: 10.1007/s10640-011-9538-y.

Res, C., Roncoli, C., Ingram, K. and Kirshen, P. (2001), "The costs and risks of coping with drought: livelihood impacts and farmers' responses in Burkina Faso", Climate Research, Vol. 19, pp. 119-132.

Res, C., Vogel, C. and Brien, K.O. (2006), "Who can eat information?", Examining the Effectiveness of Seasonal Climate Forecasts and Regional Climate-Risk Management Strategies, Vol. 33 No. July 2002, pp. 111-122.

Tadesse, T., Hassan, R.M., Ringler, C., Alemu, T. and Yesuf, M. (2009), "Determinants of farmers' choice of adaptation methods to climate change in the nile basin of Ethiopia determinants of farmers' choice of adaptation methods to climate change in the nile basin of Ethiopia", Global Environmental Change, doi: 10.1016/j.gloenvcha.2009.01.002.

Wang, J., Mendelsohn, R., Dinar, A., Huang, J., Rozelle, S. and Zhang, L. (2009), "The impact of climate change on China's agriculture", Agricultural Economics, Vol. 40 No. 3, pp. 323-337, doi: 10.1111/ j.1574-0862.2009.00379.x.

Wozniak, G.D. (1975), "The adoption of interrelated innovations: a human capital approach", The Review of Economics and Statistics, Vol. 1970, pp. 70-79.

Corresponding author

Chandan Kumar Jha can be contacted at: chandan1929@gmail.com

For instructions on how to order reprints of this article, please visit our website:

www.emeraldgrouppublishing.com/licensing/reprints.htm

Or contact us for further details: permissions@emeraldinsight.com 